Introduction: Recent research indicates rise in incidence of overweight and obesity among children and young people. The research focused on assessment of the influence of a comprehensive rehabilitation programme with an element of increased physical activity on fitness of children and adolescents. The research and analysis involved 434 children with diagnosed overweight and ordinary obesity in the following age groups: 8-12, 13-15, 16-18 years, qualified for the programme by the attending physician at the health resort. The research also took into account age, sex and BMI at the beginning and at the end of the stay. The patients were treated in our institution during $27 \mathrm{~d}$. Physical fitness was assessed through Eurofit fitness tests at the Jagusia Health Resort Hospital for Children in Kudowa-Zdroj at the beginning and at the end of their stay in the health resort.

Method: Each child had eight types of tests including such elements of physical fitness as: agility, force, strength, muscle endurance, suppleness, speed, balance, respiratory and circulatory endurance. Sequence of motricity tests included: balance on one leg, movement speed of the upper limb, bend forward in the sit down position, long jump off the spot, clenching fists, sit ups from lying down position, bent arm hang and shuttle run $10 \times 5 \mathrm{~m}$.

Results: Results of the research indicate a significant decrease of the BMI of the examined groups - on average by $5.7 \mathrm{~kg}$, correlation between the body weight and physical fitness in individual fitness tests and better final results in comparison to the initial values in fitness tests (except for tests of movement speed of the upper limb).

Conclusions: Conclusions of the research indicate that the comprehensive programme for treatment of overweight and obesity among children and adolescents during rehabilitation stays results in decrease of weight and improvement of physical fitness.

\title{
42 - Obesity related to free time activities in Portuguese children
}

\author{
I Mourao-Carvalhal, E Coelho, S Fonseca and V Rodrigues \\ CIDESD, University of Tras-os-Montes e Alto Douro, Portugal
}

Introduction: The purpose of the present study was to assess the association among free time activities, body image perception and obesity.

Method: The sample included 588 children (269 girls and 319 boys) from elementary and secondary school (10.8 (SD $2 \cdot 8$ ) years old). Obesity was estimated by BMI and the cutoff points of Cole et al. (2000). A questionnaire was completed by parents and children to provide information about age, hours spent per week and weekend in screen activities (TV, electronic games, internet), playing, studying, doing physical activity, the use of public spaces (playground, gymnasium, swimming pool, gardens) and body image perception (Stunkard's silhouettes).
Results: The results from binary logistic regression were only significant for age $(\mathrm{OR}=0 \cdot 807 ; 95 \%$ CI $0 \cdot 714,0 \cdot 911)$, playing at weekend $(\mathrm{OR}=0 \cdot 678 ; 95 \% \mathrm{CI} 0 \cdot 461,0 \cdot 997)$ and body image perception (OR $=11219$; $95 \%$ CI 6988, 18010). The OR of being obese were 0.678 times less for children that play more at weekend, and 0.807 times less for older children. On the other hand, body image is a risk factor for obesity and the OR were 11219 times more for children that have the perception of a more obese image.

Conclusions: Age and playing at weekend are preventive factors; meanwhile, the perception of body image is a risk factor for obesity. These results are very important to take into account in programmes designed to combat obesity.

\section{3 - Total body percentage and motor coordination among Portuguese schoolchildren}

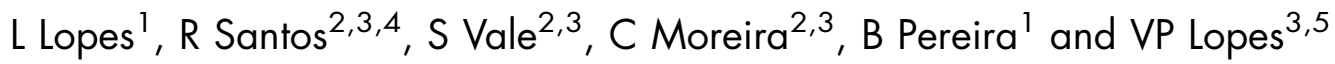

'Research Centre on Childhood Professional's Development, Institute of Education, University of Minho, Braga, Portugal: ${ }^{2}$ Research Centre for Physical Activity, Health and Leisure (CIAFEL), Faculty of Sports Science, University of Porto, Porto, Portugal: ${ }^{3}$ Maia Institute of Higher Education, Maia, Portugal: ${ }^{4}$ Research Center in Sports Sciences, Health Sciences and Human Development (CIDESD), Portugal: ${ }^{5}$ Department of Sports Science of Polytechnic Institute of Braganca, Braganca, Portugal 